\title{
Nontuberculous mycobacterial lung disease: ecology, microbiology, pathogenesis, and antibiotic resistance mechanisms
}

\author{
Su-Young Kim, Sun Ae Han*, Dae Hun Kim, Won-Jung Koh
}

Division of Pulmonary and Critical Care Medicine, Department of Medicine, Samsung Medical Center, Sungkyunkwan University School of Medicine, Seoul, Korea

Received: June 24, 2017

Revised: July 28, 2017

Accepted: July 28, 2017

Corresponding author:

Won-Jung Koh

Division of Pulmonary and Critical

Care Medicine, Department of

Medicine, Samsung Medical

Center, Sungkyunkwan University

School of Medicine, 81 Irwon-ro,

Gangnam-gu, Seoul 06351, Korea

Tel: +82-2-3410-3429

E-mail:wjkoh@skku.edu

*Su-Young Kim and Sun Ae Han contributed equally to this study as first authors.
This is an Open Access article distributed under the terms of the Creative Commons Attribution Non-Commercial License (http:// creativecommons.org/licenses/ by-nc/4.0/).

\section{ABSTRACT}

The incidence and prevalence of lung disease caused by nontuberculous mycobacteria (NTM) are increasing worldwide. Environmental sources of NTM include water, soil, and dust, and the acquisition of NTM infection depends on sufficient environmental exposure, host susceptibility factors such as immunocompromised status or cystic fibrosis, and mycobacterial virulence factors. The development of molecular methods has allowed the characterization of new species and the identification of NTM to the precise species and subspecies levels. Mycobacterium avium complex, M. abscessus complex, and $M$. kansasii are the most frequently identified organisms causing lung disease. Susceptibility to disease is incompletely understood, and thus, it is unclear what preventative measures may be effective. Additionally, NTM have natural and acquired resistance mechanisms to several antibiotics. Better understanding of the ecology, pathogenesis, and mycobacterial genetics and antibiotic resistance mechanisms is essential for preventing NTM infections and developing new regimens for effective treatment.

Keywords: Drug resistance, microbial; Ecology; Epidemiology; Etiology; Nontuberculous mycobacteria

\section{INTRODUCTION}

The term "nontuberculous mycobacteria" (NTM) generally refers to mycobacteria other than the Mycobacterium tuberculosis complex and M. leprae [1]. NTM are ubiquitous in the environment, including household water, natural water sources, and soil [2]. Human disease due to NTM is classified into four distinct clinical syndromes: chronic pulmonary disease, lymphadenitis, cutaneous disease, and disseminated disease. Of these, chronic pulmonary disease is the syndrome most commonly encountered clinically [1]. The incidence and prevalence of NTM lung disease are increasing worldwide. Common causative organisms of pulmonary infection are the slowly growing mycobacteria (SGM), including M. avium complex (MAC) and M. kansasii, and the rapidly growing mycobacteria (RGM) including M. abscessus complex (MABC).

Clinical aspects of NTM lung disease, such as epidemiology, diagnosis, and treatment, were recently reviewed [3-5]. In this article, therefore, we review the ecology, microbiology, patho- 
genesis, and antibiotic resistance mechanisms of NTM lung disease.

\section{ECOLOGY AND INFECTION ROUTE}

Understanding the physiology and structural features of NTM is the key to understanding their ecology, routes of transmission, and resistance to antibiotics and disinfectants. The lipid-rich outer envelope results in NTM cells that are impermeable to hydrophilic nutrients and resistant to heavy metals, disinfectants, and antibiotics [6-8]. Furthermore, the extreme hydrophobicity of the NTM envelope results in cells that prefer surface attachment during growth (i.e., biofilm formation) in the environment and in tissue rather than growing in a planktonic state. Growth in biofilms further increases the resistance of NTM cells to disinfectants and antibiotics [9]. The combination of the impermeable envelope and the low number ( 1 or 2 ) of ribosomal RNA ( $r R N A$ ) operons contributes to the slow growth of NTM (one generation per day) [10]. Unlike members of the $M$. tuberculosis complex, the NTM are free-living bacteria and not obligate parasites of humans. NTM are normal inhabitants of natural soils and water and thereby enter drinking-water treatment plants. From surface waters, the particulate-attached NTM enter the water treatment plants. NTM are approximately 10 to 100 times more resistant to chlorine, chloramine, chlorine dioxide, and ozone compared to Escherichia coli [11], and as a result, NTM can survive in water distribution systems [12]. In these distribution systems, the hydrophobic NTM attach to pipe surfaces and form biofilms [13], which prevent these slowly growing bacteria from being washed out of the systems. The major determinants of NTM growth and persistence in water distribution systems are the levels of disinfectant and of reduced organic carbon, but NTM are disinfectant-resistant compared to many other bacteria, and in the absence of competitors, the NTM can utilize all the available organic carbon [12]. From the distribution systems, NTM enter the plumbing of homes, hospitals, long-term care facilities, and office buildings. NTM numbers increase appreciably in water heating systems, and thereby, higher numbers enter premise plumbing. Premise plumbing is an ideal habitat for NTM: the water is warm, there are plenty of surfaces for biofilm formation, and there are few competitors for the limited nutrients. Although NTM can be recovered from premise plumbing water samples in the range of 100 to 1,000 colony-forming unit (CFU)/mL, many more NTM cells are present in biofilms $\left(10,000 \mathrm{CFU} / \mathrm{cm}^{2}\right)[12]$. The ability of NTM to grow at low oxy- gen concentrations means that they can persist and grow in low oxygen habitats such as biofilms. Also, NTM are relatively resistant to high temperature [14]. The time necessary to kill $90 \%$ of $M$. avium cells is 1,000 minutes at $50^{\circ} \mathrm{C}, 54$ minutes at $55^{\circ} \mathrm{C}$, and 4 minutes at $60^{\circ} \mathrm{C}$ [14]. For $M$. intracellulare, the time necessary to kill $90 \%$ of cells is 550 minutes at $50^{\circ} \mathrm{C}, 24$ minutes at $55^{\circ} \mathrm{C}$, and 1.5 minutes at $60^{\circ} \mathrm{C}$ [14]. NTM are frequently isolated from household plumbing where the water heater temperature is $50^{\circ} \mathrm{C}$ or lower [15].

The major route of NTM infection leading to pulmonary disease is via aerosols. M. avium and $M$. intracellulare are readily aerosolized from water, and their cell concentrations in aerosolized droplets can be some 1,000- to 10,000-fold higher than in a cell suspension [16]. Aerosolized NTM cells are further associated with droplets small enough ( $\leq 1 \mu \mathrm{m}$ in diameter) to enter the alveoli [16]. Although individuals are infected by NTM in aerosols generated by splashing water in showers or sinks, it is the NTM in biofilms that ensure the persistence of NTM in premise plumbing. Furthermore, NTM in biofilms, as is the case with other bacteria, are even more resistant to disinfectants than those in water [17]. The high prevalence of NTM in premise plumbing was confirmed in a study of showerheads across the United States, which found that $70 \%$ of showerheads had NTM [18]. M. avium cells in a showerhead were shown to be identical by DNA fingerprinting to $M$. avium cells isolated from the patient using the shower [13]. In another study, half of 30 households of NTM-infected patients had NTM species that were identical by DNA fingerprinting to the species infecting them [15]. Wallace et al. [19] evaluated MAC household water isolates from three published studies and 37 additional MAC respiratory disease patients. The water and biofilm samples were obtained from 752 individual sites in 80 households of 73 NTM patients. Although M. intracellulare was identified by nonsequencing methods in 41 household water/ biofilm samples, internal transcribed spacer sequencing revealed that none of the samples contained $M$. intracellulare and that 30 samples were $M$. chimaera, eight were other MAC $X$ species, and three were M. avium [19]. In comparison, M. avium was recovered from 144 (19.1\%, 144/752) water/biofilm samples [19]. These results indicate that, although household water is a probable source of infection by $M$. chimaera and some other MAC species, $M$. intracellulare lung disease in the United States is acquired from environmental sources other than household water.

Although not as emphasized as waterborne NTM infection, NTM in soil have also been linked to pulmonary disease. Dusts generated during the handling of potting soil are rich 
in NTM [20], and a substantial proportion of dustborne NTM are associated with particles small enough ( $\leq 1$ to $2 \mu \mathrm{m}$ in diameter) to enter lung alveoli [20]. In a comparison of NTM isolates from patients with those from dusts generated by soil samples that the patients used in gardening, five of 11 patients were infected with genetically the same isolate that was found in the soils [20]. In Japan, NTM were detected in soil and house-dust samples [21]. MAC strains were recovered from $48.9 \%$ of residential soil samples in households of 100 pulmonary MAC patients and 35 non-infected control subjects. The frequency of MAC recovery did not differ among soil types [21]. In addition, a subsequent report showed that high exposure to soil ( $\geq 2 \mathrm{hr} / \mathrm{wk}$ ) was associated with polyclonal and mixed mycobacterial MAC infections in pulmonary MAC disease patients [22].

In general, though, the modes of NTM transmission to humans have not been well defined. Unlike tuberculosis, person-to-person transmission has not been convincingly demonstrated. However, studies on potential transmission of NTM between cystic fibrosis patients have been aided in recent years by the implementation of whole-genome sequencing (WGS), which can identify strains with an extremely high level of accuracy. The first application of WGS for an NTM survey was performed by Bryant et al. [23] who investigated how $M$. abscessus subsp. massiliense was acquired by individuals with cystic fibrosis. M. abscessus subsp. massiliense isolates from 31 patients with cystic fibrosis in the United Kingdom between 2007 and 2011 were subjected to WGS and phylogenetic analysis. Isolates from 11 patients with $M$. abscessus subsp. massiliense were nearly identical, differing by fewer than ten base pairs, which strongly indicated between-patient transmission. Moreover, additional analysis provided evidence for transmission of drug-resistant strains. However, the study was inconclusive as to whether transmission occurred directly between patients or indirectly, such as via contamination of patient treatment facilities [23]. In another study, $27 \mathrm{M}$. abscessus isolates from 20 pediatric cystic fibrosis patients were examined by WGS, but most isolates were unrelated, differing by at least 34 single nucleotide polymorphisms (SNPs) from any other isolate [24]. The strongest evidence for cross-transmission was found for two siblings whose isolates differed by a maximum of 17 SNPs [24]. However, in another study by Bryant and colleagues [25], WGS was used to examine a global collection of clinical isolates, including 1,080 clinical isolates of $M$. abscessus obtained from 517 patients in United Kingdom cystic fibrosis clinics and regional reference laboratories in other countries, e.g., cystic fibrosis centers in the United States, the Republic of Ireland, Europe, and Australia. This study showed that the majority of $M$. abscessus infections are acquired through transmission, potentially via fomites and aerosols, of recently emerged, dominant circulating clones that have spread globally in cystic fibrosis patients [25].

To explore the mechanisms associated with the global spread of infection and NTM transmission routes, an epidemiological, population-wide genotyping survey would be useful. WGS will improve NTM surveys, allowing the mechanisms for the global spread of NTM disease to become clearer in the near future.

\section{MICROBIOLOGY}

\section{Runyon classification}

Historically, NTM have been divided by Runyon criteria according to their differences in growth rate on solid culture and in pigment formation [26-28]. On the basis of these criteria, NTM have been divided into four groups (Table 1). Runyon I, II, and III organisms consist of SGM (defined as having colonies maturing in more than 1 week), whereas Runyon IV consists of RGM (defined as having colonies maturing in less than 1 week).

Runyon I organisms, called "photochromogens," produce a yellow or orange pigment when exposed to light and include M. kansasii, M. marinum, and M. simiae species. Runyon II organisms, called "scotochromogens," produce a yellow-orange pigment regardless of whether they are exposed to dark or light, and this group includes $M$. scrofulaceum, $M$. szulgai, and M. gordonae species. Runyon III organisms are "nonchromogens" and do not produce pigment under any culture condition; the group includes MAC, $M$. ulcerans, $M$. xenopi, M. malmoense, M. terrae complex, M. haemophilum, and $M$. genavense species. Runyon IV organisms, in common with Runyon III organisms, do not produce pigment. However, Runyon IV species have faster growth rates. This group includes MABC, M. chelonae, and M. fortuitum complex (Table 1) $[29,30]$.

Among the more than 170 known NTM species, M. kansasii (Runyon I), MAC (Runyon III), and MABC (Runyon IV) were reported as major pathogens in NTM lung disease and ones that continue to emerge worldwide [31-33].

\section{M. avium complex}

MAC are widely distributed and the most common cause of NTM lung disease worldwide, including in Korea [31,32,34- 
Table 1. Classification of slowly growing mycobacteria and rapidly growing mycobacteria of NTM according to Runyon criteria

\begin{tabular}{|c|c|c|}
\hline Type of growth & Runyon classifications & Species \\
\hline \multirow[t]{3}{*}{ Slowly growing mycobacteria (colonies visible after more than 7 days) } & Runyon I (photochromogens) & $\begin{array}{l}\text { Mycobacterium kansasii } \\
\text { M. marinum } \\
\text { M. simiae }\end{array}$ \\
\hline & Runyon II (scotochromogens) & $\begin{array}{l}\text { M. scrofulaceum } \\
\text { M. szulgai } \\
\text { M. gordonae }\end{array}$ \\
\hline & Runyon III (nonchromogens) & $\begin{array}{l}\text { M. avium complex } \\
\text { M. genavense } \\
\text { M. haemophilum } \\
\text { M. malmoense } \\
\text { M. terrae complex } \\
\text { M. ulcerans } \\
\text { M. xenopi }\end{array}$ \\
\hline Rapidly growing mycobacteria (colonies visible in fewer than 7 days) & Runyon IV & $\begin{array}{l}\text { M. abscessus complex } \\
\text { M. chelonae } \\
\text { M. fortuitum complex }\end{array}$ \\
\hline
\end{tabular}

NTM, nontuberculous mycobacteria.

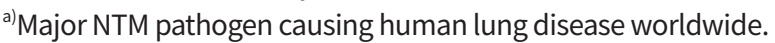

37]. In the early 1980 s, the complex was originally composed of two primary species, $M$. avium and $M$. intracellulare, which cannot be differentiated through traditional physical and biochemical methods [38]. However, with the development of molecular identification methods, several new species that are closely related to $M$. intracellulare have been identified: M. chimaera, M. colombiense, M. arosiense, M. vulneris, $M$. marseillense, $M$. timonense, $M$. bouchedurhonense, $M$. mantenii, M. yongonense, M. paraintracellulare, and "M. indicus pranii" [39-49]. In addition, M. avium has been further subdivided into four subspecies: $M$. avium subsp. avium, $M$. avium subsp. hominissuis, M. avium subsp. paratuberculosis, and $M$. avium subsp. silvaticum [50,51].

MAC are commonly and widely isolated from soil, house dust, and water [16,52-56]. Many studies also report detection of MAC in sputum, sinus, and variable water samples [15,57-61]. Interestingly, previous studies have suggested household water (especially from bathroom showers) as a source of MAC in lung disease $[13,15,18,57,58]$. However, a recent epidemiological investigation suggested that $M$. intracellulare lung disease is acquired from environmental sources other than household water [19], indicating that different MAC subspecies may have different habitats.

\section{M. kansasii}

M. kansasii is the second most common cause of NTM lung disease after MAC in some countries $[1,33,62]$. However, in
Korea, M. kansasii is a relatively uncommon cause of NTM lung disease $[4,63,64]$. In addition, infection by $M$. kansasii may occur via an aerosol route, with low infectivity in regions of endemicity [65]. Unlike other common NTM, M. kansasii is infrequently isolated from natural water sources or soil [66]. Although it is not known with certainty, the major reservoir of $M$. kansasii appears to be tap water [67].

Through various molecular analyses, $M$. kansasii has been divided into five subtypes $[68,69]$. Among $M$. kansasii clinical isolates, subtype I is the predominant subtype and is responsible for most human infections in the United States, Europe, and Japan. However, studies on the distribution and prevalence of subtypes of $M$. kansasii in Korea are very insufficient.

\section{M. abscessus complex}

Among RGM, MABC are the most common mycobacteria involved in pulmonary infections and have emerged as important human pathogens responsible for a wide spectrum of soft-tissue infections [70-72]. Separated from the $M$. chelonae group in 1992, MABC was recently differentiated into three subspecies (M. abscessus subsp. abscessus, M. abscessus subsp. massiliense, and M. abscessus subsp. bolletii) [73]. $M A B C$ is also extensively found in soil and water, in common with other NTM [74]. Previous studies revealed that $M A B C$ infections can be acquired in the community or in the hospital environment $[75,76]$. In the community environment, water supply systems are regarded as likely sources of 
MABC infection, and in the hospital environment, contamination of medical devices and water are considered to be potential sources of MABC infections [77]. Although MAC are the most common NTM species responsible for disease, the natural resistance of $\mathrm{MABC}$ to many antibiotics makes infections with the latter more difficult to treat [78-81].

\section{Genetic difference between SGM and RGM}

M. tuberculosis and M. leprae, which cause the serious human diseases of tuberculosis and leprosy, respectively, are SGM [82]. MAC and M. kansasii are also SGM and are major pulmonary pathogens worldwide [1]. It is believed that SGM evolved from RGM $[83,84]$.

Since the 2000s, there has been an increasing number of studies analyzing the genetic differences between SGM and RGM using genome sequencing. For example, ESX-5 (VMware Inc., Palo Alto, CA, USA), one of the type VII secretion systems (T7S) that secrete proteins across the unusual mycobacterial cell envelope, is only present in SGM and is a marker for distinguishing between SGM and RGM $[83,85,86]$.

More recently, Wee and colleagues [87] compared the genomes of 28 mycobacterial species to improve understanding of the distinction between RGM and SGM. The SGM were found to have lost genes (LivFGMH operon, shaACDEFG genes, and the MspA porin gene) associated with growth rates in other bacteria. Furthermore, among RGM, M. abscessus had a high number of species-specific genes, some associated with quorum sensing and which might be related to bacterial survival. Based on these analyses, the authors suggested that the mycobacterial genus has undergone a series of gene gain and loss events in the course of its evolution, which likely enabled the various species to adapt to different environments and led to the evolution of the present-day SGM and RGM groups [87].

\section{PATHOGENESIS}

\section{Host factors}

Despite the fact that NTM are widespread in the environment and that exposure to these organisms is inevitable, NTM lung disease is relatively uncommon, suggesting that normal host defense mechanisms are sufficient to prevent NTM infection and that patients who develop NTM lung disease likely have specific susceptibility factors that make them vulnerable to these infections [88].

A number of diseases associated with structural lung damage have been recognized as predisposing patients to NTM lung disease. Chronic obstructive pulmonary disease (COPD) has frequently been associated with NTM lung disease [8992]. COPD is a chronic, progressive lung disease characterized by airflow limitation with poor reversibility. Lung injury, triggered most often by smoking, causes inflammation, tissue destruction, and remodeling of elastin and collagen, with occlusion of small airways by narrowing, obliteration, and mucus plugs [93]. The heightened susceptibility to infection was demonstrated in a prospective cohort study of COPD patients with exacerbations where $22 \%$ of subjects were culture-positive for NTM [94]. The extent to which NTM infection may promote COPD has been investigated and might partly explain the apparent high frequency of mycobacterial isolation from COPD patients [95].

Cystic fibrosis, an autosomal recessive disease due to mutations in the cystic fibrosis transmembrane conductance regulator (CFTR), is strongly associated with bronchiectasis and pulmonary NTM infections, with prevalence rates of NTM in cystic fibrosis patients ranging from $6.6 \%$ to $13.7 \%$ [96-99]. However, when pulmonary NTM infection was investigated in patients with cystic fibrosis who were more than 40 years of age, the rates were closer to $50 \%$ [97].

In recent years, the relationship between NTM and noncystic fibrosis bronchiectasis has been further elucidated [100]. NTM can cause bronchiectasis by destroying the bronchial anatomy, and bronchiectasis can predispose patients to NTM colonization/disease due to impaired host local defenses $[101,102]$. NTM lung disease in bronchiectasis can also be complicated by coinfection with other bacteria, especially Pseudomonas aeruginosa [103], and fungi, including Aspergillus species [104]. Bronchiectasis and other forms of lung damage caused by concurrent or prior pulmonary tuberculosis are also associated with NTM infection; whether this predisposition is due to local impairment in host defenses from lung damage or to a common underlying immunological defect is unknown $[105,106]$. NTM are frequently found in respiratory specimens from patients with pulmonary tuberculosis, but the clinical significance of the NTM in this setting is unclear [107-109]. In a systematic review, the overall prevalence of NTM among patients with bronchiectasis was 9.3\%. Subgroup analysis revealed that the prevalence was higher in studies with a larger sample size, year of study of 2002 or afterwards, and Asian locations [110].

NTM lung disease are common in patients with primary ciliary dyskinesia, an increasingly recognized recessive disorder affecting ciliary function of the respiratory tract, sperm tails, cilia of the embryonic node, and the fallopian tubes [111]. 
Clinical manifestations of primary ciliary dyskinesia include recurrent respiratory tract infections, chronic sinusitis, rhinitis, otitis media, infertility, and laterality defects such as situs inversus totalis or heterotaxy [112]. More than $15 \%$ of patients with primary ciliary dyskinesia have at least one sputum culture positive for NTM infection [111].

However, it is increasingly recognized that NTM lung disease may occur in patients without underlying lung disease. This discovery was first described in the early 1990s in a cohort of postmenopausal women who had no predisposing lung disease [113]. Lady Windermere syndrome was the eponym applied to the condition of these patients, who tend to be taller and leaner with more scoliosis, pectus excavatum, and mitral valve prolapse than their peers $[114,115]$. These patients have increased prevalence of heterozygous mutations in CFTR (up to $50 \%$ of cases), usually without a clinical diagnosis of cystic fibrosis $[114,116]$. Several obvious family clusters in a dominant pattern indicate that genetic factors probably underlie at least some cases of NTM lung disease [117]. Defects that overlap with primary ciliary dyskinesia including impaired nasal nitric oxide concentration, low ciliary-beat frequency, and impaired Toll-like responses in respiratory epithelial cells were also reported in these patients [118]. Despite extensive study, no reproducible defect in immune function in adult patients with isolated lung disease has been found $[114,115,119]$. The absence of consistent immunological abnormalities, the late age of disease onset, and the lack of disseminated disease in patients with extensive and fatal pulmonary disease (and vice versa) suggest that NTM lung disease in these patients is not due to a major underlying immune defect. Recent whole-exome studies suggest that patients with Lady Windermere syndrome have a complex condition involving additive genetic variants in immune, ciliary, connective tissue, and CFTR genes [120].

\section{Host genetic susceptibility}

Host defense against mycobacteria depends on the action of cell-mediated immunity, effected by interactions between the myeloid (monocytes, macrophages, and dendritic cells) and the lymphoid cells ( $T$ cells and natural killer cells) [121]. The critical effector cell for controlling NTM is the macrophage, which ingests the mycobacteria. Once engulfed by the macrophage, the bacteria's fate, whether destruction, persistence, or replication, is determined by the cell's state of immune activation, with this activation determined by interactions between cells in the TH1 pathway and their associated cytokines, particularly the interleukin 12 (IL-12)/interferon $\gamma($ IFN- $\gamma)$ axis. Mononuclear phagocytes engulf mycobacteria and produce IL-12, which stimulates T cells and natural killer cells through the IL-12 receptor [121]. STAT4 (signal transducer and activator of transcription 4) is activated, leading to induction of IFN- $\gamma$ production, which binds to its receptor, causing activation and differentiation of macrophages with further upregulation of the expression of IL-12 and tumor necrosis factor $\alpha$ (TNF- $\alpha)[122,123]$. The activated macrophages are then able to kill intracellular organisms such as NTM. Numerous other cytokines (e.g., IL-18, IL-23, and IL-29), receptors (e.g., vitamin $\mathrm{D}$ receptor), and unidentified cofactors may also be important.

TH1 immunity can be triggered through Toll-like receptors (TLRs), and mice lacking TLR2 were more susceptible to $M$. avium infection $[124,125]$. TLR9 signaling may also play a small role. Recent evidence suggests that NTM initially trigger immunity via the AIM2 (absent in melanoma 2)-inflammasome, whereas M. tuberculosis does so via NLRP3 (nucleotide-binding domain, leucine rich family [NLR], pyrin containing 3 gene) [126].

In addition to CD4 cells, IL-12 was also implicated in TNF- $\alpha$ production by NK cells in M. avium infections [127]. An early role for IL-6 was suggested, as was a late response involving IL-10 [128]. More recently, a role for TNF- $\alpha$ has been illustrated by infections occurring in patients treated with anti-TNF- $a$ biologic reagents for rheumatoid arthritis $[129,130]$.

Mendelian susceptibility to mycobacterial disease comprises several disorders related to IFN- $\gamma$ production deficits or poor responsiveness to IFN- $\gamma$ due to receptor abnormalities or deficiencies $[131,132]$. There are at least seven autosomal mutations and two X-linked mutations that have been associated with disseminated disease, usually occurring in childhood [121]. Three of the autosomal genes are implicated in the control of IFN- $\gamma$ production: IL12B, IL12RB1, and ISG15 (interferon-stimulated gene 15) $[121,133]$. Four other autosomal genes are implicated in IFN- $\gamma$ responsiveness: IFNGR1 (interferon $\gamma$ receptor 1), IFNGR2, STAT1, and IRF8 (interferon regulatory factor 8) [134]. Specific mutations in IKBKG (inhibitor of nuclear factor $\mathrm{kB}$ kinase subunit $\gamma$ ) and CYBB (cytochrome b a [CYBA] and $\beta$ ) cause X-linked Mendelian susceptibility to mycobacterial disease. Approximately $80 \%$ of genetically diagnosed cases are caused by IFN- $\gamma$ receptor or IL-12 receptor deficiency; however, approximately half of all patients with disseminated NTM have no discernible defects in the IL-12/IFN- $\gamma$ axis [121]. GATA2 (GATA binding protein 2) is a transcription factor implicated in early hemopoietic, lymphatic, and vascular development, and deficiency gives rise 
to a wide range of disease phenotypes previously called the "monocytopenia with M. avium complex syndrome" [121]. Infections can present from age 3 to 80 years with profoundly decreased or absent circulating monocytes, dendritic cells, natural killer cells, and B cells [121]. Anti-IFN- $\gamma$ autoantibodies cause an acquired susceptibility to NTM $[135,136]$, and all cases present in adults, usually with high-titer neutralizing antibodies against IFN- $\gamma$. Most patients outside of Asia are female, but the gender distribution in Asia is equal. These patients often present with other intracellular pathogens but, interestingly, not M. tuberculosis [135,136].

\section{ANTIBIOTIC RESISTANCE MECHANISMS}

Since the genome sequence of M. tuberculosis H37Rv was determined [137], resistance mechanisms against several antibiotics used for treatment of mycobacterial diseases, including those caused by NTM, have been identified at the genome level. Previous studies reported that NTM have natural and acquired antibiotic-resistance mechanisms to several antibiotics and that some of these mechanisms are very similar to those of M. tuberculosis [138]. This section will briefly describe studies on natural and acquired resistance to several antibiotics in NTM (Table 2).

\section{Natural antibiotic resistance}

The cell envelope of NTM is a hydrophobic, waxy, impermeable barrier, rich in complex lipids, and thicker than the walls of other bacteria [6]. These features of the cell envelope make NTM naturally resistant to physical and chemical environmental stresses, including antimicrobial agents [139]. In 1994, Jarlier and Nikaido [7] first reported low permeability as contributing to natural antibiotic resistance and that the high lipid content of the cell envelope was the main factor in this low permeability.

The erythromycin ribosomal methylase (erm) gene family contributes to resistance to macrolides, which are among the main antibiotics used for treatment of NTM disease [140]. The erm genes confer inducible macrolide resistance, which, in $M$. abscessus, can be ablated by a single nucleotide change at position 28 of the erm (41) gene; a functional erm (41) gene in $M$. abscessus is an important factor in the inducible resistance of many clinical isolates to macrolides [141]. Not all NTM have functional erm genes, but their presence in $M$. smegmatis, M. abscessus, M. bolletii, and M. fortuitum explains the intrinsic macrolide resistance of these species $[140,142,143]$.

Some of the NTM (M. abscessus, M. chelonae) and M. tuberculosis exhibit intrinsic high-level resistance to ethambutol, and this resistance is due to the presence of variant nucleotides within the conserved ethambutol resistance-determining region (ERDR) in embB $[144,145]$. In addition, the quinolone resistance-determining regions ( $Q R D R)$ in the $A$ and $B$ subunits of DNA gyrase (genes gyrA and gyrB) were also identified in NTM $[146,147]$. According to these studies, resistance rates to quinolone differ according to the differences in specific regions of gyrA and gyrB, which are conserved in the NTM.

The whiB gene family includes transcriptional regulators that contribute to intrinsic antibiotic resistance in mycobacteria, including NTM $[148,149]$. Morris and colleagues [149] found that a null mutant of $M$. tuberculosis whiB7 was susceptible to a wide spectrum of antibiotics, and M. smegmatis and $M$. bovis mutants lacking whiB7 genes also showed the same susceptibility pattern as that of the M. tuberculosis mutant.

Table 2. Summary of types of antibiotic resistance and associated resistance mechanisms in nontuberculous mycobacteria

\begin{tabular}{|c|c|c|c|}
\hline Type of resistance & Associated gene or cell component & Mechanism & Antibiotic \\
\hline \multirow[t]{6}{*}{ Natural resistance } & Cell envelope & Low permeability & $\beta$-Lactams \\
\hline & erm gene & Polymorphisms in erm & Inducible resistance to macrolides \\
\hline & Ethambutol resistance-determining region & Polymorphisms in embB & Ethambutol \\
\hline & Quinolone resistance-determining region & Polymorphisms in gyrA and gyrB & Quinolone \\
\hline & whiB gene & Presence of whiB & Large spectrum of antibiotics \\
\hline & Efflux pump system & Function of MmpL transporter & Clofazimine, bedaquiline, thiacetazone \\
\hline \multirow[t]{3}{*}{ Acquired resistance } & rpoB gene & Mutation of $r p o B$ & Rifampin \\
\hline & 23S rRNA gene $(r r l)$ & Mutation of $r r l$ & Macrolides \\
\hline & 16S rRNA gene (rrs) & Mutation of $r r s$ & Aminoglycosides \\
\hline
\end{tabular}

erm, erythromycin ribosomal methylase; gyr, subunits of DNA gyrase; whiB, transcriptional regulator whiB; MmpL, mycobacterial membrane protein large; $r p o B, \beta$ subunit of bacterial RNA polymerase; rRNA, ribosomal RNA. 
Efflux pump systems are important antibiotic-resistance mechanisms in multidrug resistant (MDR) pathogens, and genes encoding their proteins can be located on chromosomes or plasmids $[150,151]$. The role of efflux pump systems in antibiotic resistance of NTM has been investigated, and there is some similarity in the mechanism and structure of these efflux pumps with those of M. tuberculosis [152-154]. Among the classes of efflux pump systems, mycobacterial membrane protein large ( $\mathrm{MmpL}$ ) and small (MmpS) transporters have emerged as key factors in antibiotic resistance in NTM $[155,156]$. MmpLs belongs to the resistance-nodulation-cell division permease superfamily [157]. Since Pasca and colleague [158] first reported that the $m m p L 7$ gene from $M$. tuberculosis conferred resistance to isoniazid when overexpressed in $M$. smegmatis, orthologs of $\mathrm{mmpL}$ and $\mathrm{mmpS}$ genes have been characterized and identified in NTM [159]. Recently, several studies have implicated MmpS5/MmpL5-mediated efflux pump systems in antibiotic resistance in NTM. Mutations of the $\mathrm{mmpS5} / \mathrm{mmpL5}$ operon were associated with resistance to bedaquiline and clofazimine in $\mathrm{M}$. intracellulare and to thiacetazone in M. abscessus $[159,160]$. Further research may also reveal roles for other efflux pumps of NTM, such as the $m m p L$ gene, in antibiotic resistance.

\section{Acquired antibiotic resistance}

The acquisition of resistance by major pathogens is very likely to occur during antibiotic treatment and is mostly caused by mutation of the related genes $[161,162]$. Due to this acquired resistance, MDR pathogens are rapidly increasing worldwide. The basis for acquired resistance is not always readily identifiable due to interactions among several genes. To date, acquired resistance mechanisms for rifampin, macrolides, and aminoglycosides have been identified in NTM.

Rifampin is the antibiotic primarily used in diseases caused by M. kansasii and MAC [163]. However, acquired rifampin resistance has been documented in MAC and $M$. kansasii and is associated with the $\beta$ subunit of bacterial RNA polymerase $(r p o B)$ gene. Mutations within the 81-bp core region of $r p o B$ and in other regions of this gene confer rifampin resistance in $M$. kansasii and MAC, and some of these mutations of $r p o B$ have previously been described in rifampin-resistant $M$. tuberculosis isolates $[163,164]$.

Macrolides (clarithromycin and erythromycin) are the antibiotics most commonly used in the treatment of NTM, but there are many reports of NTM that are resistant to these antibiotics [1]. A single point mutation at positions 2058 or 2059 (A2058G, A2058C, A2058T, A2059T, A2059C, and A2059G) (E. coli numbering) of the 23S rRNA gene ( $r r l)$ is associated with high-level macrolide resistance in several NTM, including MABC, MAC, M. chelonae, M. fortuitum, and M. kansasii [165169]. More recently, Mougari and colleagues [170] identified single point mutations of the $\mathrm{rl}$ when selecting for macrolide-resistance mutations in MABC in vitro. However, they found that acquisition of macrolide resistance by $\mathrm{rrl}$ mutation was more common in isolates of MABC lacking a functional erm(41) gene.

The 2-deoxystreptamine aminoglycosides, including kanamycin, amikacin, gentamicin, and tobramycin, are important drugs for the treatment of MDR NTM and M. tuberculosis infection [171]. However, acquired resistance mechanisms for 2-deoxystreptamine aminoglycosides have also been demonstrated in NTM by Prammananan et al. [172] and Wallace et al. [173]. According to these studies, M. abscessus showed a very high resistance rate to kanamycin, amikacin, and tobramycin due to a single mutation at position 1408 (A1408G) (E. coli numbering) of the $16 \mathrm{~S}$ rRNA gene ( $r r s$ ). In addition, mutations of positions 1406, 1409, and 1491 of rrs (T1406A, C1409T, and G1491T) as well as position 1408 were associated with aminoglycoside resistance [174]. Other researchers have also reported that $r$ s mutations are associated with aminoglycoside resistance in mycobacteria other than $M$. $a b$ scessus [175-177].

\section{CONCLUSION}

The incidence and prevalence of NTM lung disease are increasing worldwide, and NTM have natural and acquired resistance mechanisms to several antibiotics used in treatment. NTM infection depends on sufficient environmental exposure, host susceptibility factors, and mycobacterial virulence factors. Further knowledge of the ecology and transmission routes of these organisms, as well as host-pathogen interactions, will enable better interventions to both prevent and treat NTM disease.

\section{CONFLICTS OF INTEREST}

No potential conflict of interest relevant to this article was reported.

\section{ACKNOWLEDGMENTS}

This study was funded by the Medical Research Fund of Samsung Medical Center (SMO1140221 and SMO1151351). 


\section{ORCID}

Su-Young Kim https://orcid.org/0000-0002-6369-3399

Sun Ae Han https://orcid.org/0000-0003-1219-8096

Dae Hun Kim https://orcid.org/0000-0001-8599-8583

Won-Jung Koh https://orcid.org/0000-0002-4756-3527

\section{REFERENCES}

1. Griffith DE, Aksamit T, Brown-Elliott BA, Catanzaro A, Daley C, Gordin F, et al. An official ATS/IDSA statement: diagnosis, treatment, and prevention of nontuberculous mycobacterial diseases. Am J Respir Crit Care Med 2007;175:367-416.

2. Falkinham JO 3rd. Environmental sources of nontuberculous mycobacteria. Clin Chest Med 2015;36:35-41.

3. Ryu YJ, Koh WJ, Daley CL. Diagnosis and treatment of nontuberculous mycobacterial lung disease: clinicians' perspectives. Tuberc Respir Dis (Seoul) 2016;79:74-84.

4. Kwon YS, Koh WJ. Diagnosis and treatment of nontuberculous mycobacterial lung disease. J Korean Med Sci 2016;31:649-59.

5. Kang YA, Koh WJ. Antibiotic treatment for nontuberculous mycobacterial lung disease. Expert Rev Respir Med 2016;10:557-68.

6. Brennan PJ, Nikaido $\mathrm{H}$. The envelope of mycobacteria. Annu Rev Biochem 1995;64:29-63.

7. Jarlier V, Nikaido H. Mycobacterial cell wall: structure and role in natural resistance to antibiotics. FEMS Microbiol Lett 1994;123:11-8.

8. Rastogi N, Frehel C, Ryter A, Ohayon H, Lesourd M, David $\mathrm{HL}$. Multiple drug resistance in Mycobacterium avium: is the wall architecture responsible for exclusion of antimicrobial agents? Antimicrob Agents Chemother 1981; 20:666-77.

9. Falkinham JO 3rd. Growth in catheter biofilms and antibiotic resistance of Mycobacterium avium. J Med Microbiol 2007;56:250-4.

10. Bercovier H, Kafri O, Sela S. Mycobacteria possess a surprisingly small number of ribosomal RNA genes in relation to the size of their genome. Biochem Biophys Res Commun 1986;136:1136-41.

11. Taylor RH, Falkinham JO 3rd, Norton CD, LeChevallier MW. Chlorine, chloramine, chlorine dioxide, and ozone susceptibility of Mycobacterium avium. Appl Environ Microbiol 2000;66:1702-5.

12. Falkinham JO 3rd, Norton CD, LeChevallier MW. Factors influencing numbers of Mycobacterium avium, Mycobacterium intracellulare, and other Mycobacteria in drinking water distribution systems. Appl Environ Microbiol 2001;67:1225-31.

13. Falkinham JO 3rd, Iseman MD, de Haas P, van Soolingen D. Mycobacterium avium in a shower linked to pulmonary disease. J Water Health 2008;6:209-13.

14. Schulze-Robbecke R, Buchholtz K. Heat susceptibility of aquatic mycobacteria. Appl Environ Microbiol 1992;58: 1869-73.

15. Falkinham JO 3rd. Nontuberculous mycobacteria from household plumbing of patients with nontuberculous mycobacteria disease. Emerg Infect Dis 2011;17:419-24.

16. Parker BC, Ford MA, Gruft H, Falkinham JO 3rd. Epidemiology of infection by nontuberculous mycobacteria. IV. Preferential aerosolization of Mycobacterium intracellulare from natural waters. Am Rev Respir Dis 1983;128: 652-6.

17. Steed KA, Falkinham JO 3rd. Effect of growth in biofilms on chlorine susceptibility of Mycobacterium avium and Mycobacterium intracellulare. Appl Environ Microbiol 2006;72:4007-11.

18. Feazel LM, Baumgartner LK, Peterson KL, Frank DN, Harris JK, Pace NR. Opportunistic pathogens enriched in showerhead biofilms. Proc Natl Acad Sci U S A 2009;106: 16393-9.

19. Wallace RJ Jr, lakhiaeva E, Williams MD, Brown-Elliott BA, Vasireddy S, Vasireddy R, et al. Absence of Mycobacterium intracellulare and presence of Mycobacterium chimaera in household water and biofilm samples of patients in the United States with Mycobacterium avium complex respiratory disease. J Clin Microbiol 2013;51: 1747-52.

20. De Groote MA, Pace NR, Fulton K, Falkinham JO 3rd. Relationships between Mycobacterium isolates from patients with pulmonary mycobacterial infection and potting soils. Appl Environ Microbiol 2006;72:7602-6.

21. Fujita K, Ito Y, Hirai T, Maekawa K, Imai S, Tatsumi S, et al. Genetic relatedness of Mycobacterium avium-intracellulare complex isolates from patients with pulmonary MAC disease and their residential soils. Clin Microbiol Infect 2013;19:537-41.

22. Fujita K, Ito Y, Hirai T, Kubo T, Maekawa K, Togashi K, et al. Association between polyclonal and mixed mycobacterial Mycobacterium avium complex infection and environmental exposure. Ann Am Thorac Soc 2014;11: 45-53. 
23. Bryant JM, Grogono DM, Greaves D, Foweraker J, Roddick I, Inns T, et al. Whole-genome sequencing to identify transmission of Mycobacterium abscessus between patients with cystic fibrosis: a retrospective cohort study. Lancet 2013;381:1551-60.

24. Harris KA, Underwood A, Kenna DT, Brooks A, Kavaliunaite $\mathrm{E}$, Kapatai $\mathrm{G}$, et al. Whole-genome sequencing and epidemiological analysis do not provide evidence for cross-transmission of mycobacterium abscessus in a cohort of pediatric cystic fibrosis patients. Clin Infect Dis 2015;60:1007-16.

25. Bryant JM, Grogono DM, Rodriguez-Rincon D, Everall I, Brown KP, Moreno P, et al. Emergence and spread of a human-transmissible multidrug-resistant nontuberculous mycobacterium. Science 2016;354:751-7.

26. Rogall T, Wolters J, Flohr T, Bottger EC. Towards a phylogeny and definition of species at the molecular level within the genus Mycobacterium. Int J Syst Bacteriol 1990;40: 323-30.

27. Runyon EH. Anonymous mycobacteria in pulmonary disease. Med Clin North Am 1959;43:273-90.

28. Koneman EW, Allen SD, Dowell VR Jr, Janda WM, Sommers HM, Winn WC Jr. Color atlas and textbook of diagnostic microbiology. 3rd ed. Philadelphia (PA): Lippincott; 1988.

29. Sommers HM, Good RC. Mycobacterium. In: Lennette EH, Balows A, Hausler WJ, Shadomy HJ, editors. Manual of clinical microbiology. 4th ed. Washington, DC: American Society for Microbiology; 1985. p. 216-48.

30. Wayne LG, Kubica GP. The mycobacteria. In: Sneath PH, Mair NS, Sharpe ME, Holt JG, editors. Bergey's manual of systematic bacteriology. Vol. 2. Baltimore (MD): Williams \& Wilkins; 1986. p. 1435-57.

31. Prevots DR, Marras TK. Epidemiology of human pulmonary infection with nontuberculous mycobacteria: a review. Clin Chest Med 2015;36:13-34.

32. Stout JE, Koh WJ, Yew WW. Update on pulmonary disease due to non-tuberculous mycobacteria. Int J Infect Dis 2016;45:123-34.

33. Hoefsloot W, van Ingen J, Andrejak C, Angeby K, Bauriaud $\mathrm{R}$, Bemer $\mathrm{P}$, et al. The geographic diversity of nontuberculous mycobacteria isolated from pulmonary samples: an NTM-NET collaborative study. Eur Respir J 2013;42:1604-13.

34. Koh WJ, Kwon OJ, Jeon K, Kim TS, Lee KS, Park YK, et al. Clinical significance of nontuberculous mycobacteria isolated from respiratory specimens in Korea. Chest
2006;129:341-8.

35. Sim YS, Park HY, Jeon K, Suh GY, Kwon OJ, Koh WJ. Standardized combination antibiotic treatment of Mycobacterium avium complex lung disease. Yonsei Med J 2010; 51:888-94.

36. Koh WJ, Jeong BH, Jeon K, Lee NY, Lee KS, Woo SY, et al. Clinical significance of the differentiation between Mycobacterium avium and Mycobacterium intracellulare in M. avium complex lung disease. Chest 2012;142:14828.

37. Jeong BH, Jeon K, Park HY, Kim SY, Lee KS, Huh HJ, et al. Intermittent antibiotic therapy for nodular bronchiectatic Mycobacterium avium complex lung disease. Am J Respir Crit Care Med 2015;191:96-103.

38. Daley CL. Mycobacterium avium complex disease. Microbiol Spectr 2017;5:1-36.

39. Murcia MI, Tortoli E, Menendez MC, Palenque E, Garcia MJ. Mycobacterium colombiense sp. nov., a novel member of the Mycobacterium avium complex and description of MAC-X as a new ITS genetic variant. Int J Syst Evol Microbiol 2006;56:2049-54.

40. Bang D, Herlin T, Stegger M, Andersen AB, Torkko P, Tortoli $\mathrm{E}$, et al. Mycobacterium arosiense sp. nov., a slowly growing, scotochromogenic species causing osteomyelitis in an immunocompromised child. Int J Syst Evol Microbiol 2008;58:2398-402.

41. van Ingen J, Boeree MJ, Kosters K, Wieland A, Tortoli E, Dekhuijzen PN, et al. Proposal to elevate Mycobacterium avium complex ITS sequevar MAC-Q to Mycobacterium vulneris sp. nov. Int J Syst Evol Microbiol 2009;59:227782.

42. Ben Salah I, Cayrou C, Raoult D, Drancourt M. Mycobacterium marseillense sp. nov., Mycobacterium timonense sp. nov. and Mycobacterium bouchedurhonense sp. nov., members of the Mycobacterium avium complex. Int J Syst Evol Microbiol 2009;59:2803-8.

43. van Ingen J, Lindeboom JA, Hartwig NG, de Zwaan R, Tortoli E, Dekhuijzen PN, et al. Mycobacterium mantenii sp. nov., a pathogenic, slowly growing, scotochromogenic species. Int J Syst Evol Microbiol 2009;59:2782-7.

44. Saini V, Raghuvanshi S, Talwar GP, Ahmed N, Khurana JP, Hasnain SE, et al. Polyphasic taxonomic analysis establishes Mycobacterium indicus pranii as a distinct species. PLoS One 2009;4:e6263.

45. Kim BJ, Math RK, Jeon CO, Yu HK, Park YG, Kook YH, et al. Mycobacterium yongonense sp. nov., a slow-growing non-chromogenic species closely related to Mycobacte- 
rium intracellulare. Int J Syst Evol Microbiol 2013;63: 192-9.

46. Lee SY, Kim BJ, Kim H, Won YS, Jeon CO, Jeong J, et al. Mycobacterium paraintracellulare sp. nov., for the genotype INT-1 of Mycobacterium intracellulare. Int J Syst Evol Microbiol 2016;66:3132-41.

47. Kim SY, Park HY, Jeong BH, Jeon K, Huh HJ, Ki CS, et al. Molecular analysis of clinical isolates previously diagnosed as Mycobacterium intracellulare reveals incidental findings of "Mycobacterium indicus pranii" genotypes in human lung infection. BMC Infect Dis 2015;15: 406.

48. Kim SY, Shin SH, Moon SM, Yang B, Kim H, Kwon OJ, et al. Distribution and clinical significance of Mycobacterium avium complex species isolated from respiratory specimens. Diagn Microbiol Infect Dis 2017;88:125-37.

49. Moon SM, Kim SY, Jhun BW, Lee H, Park HY, Jeon K, et al. Clinical characteristics and treatment outcomes of pulmonary disease caused by Mycobacterium chimaera. Diagn Microbiol Infect Dis 2016;86:382-4.

50. Thorel MF, Krichevsky M, Levy-Frebault VV. Numerical taxonomy of mycobactin-dependent mycobacteria, emended description of Mycobacterium avium, and description of Mycobacterium avium subsp. avium subsp. nov., Mycobacterium avium subsp. paratuberculosis subsp. nov., and Mycobacterium avium subsp. silvaticum subsp. nov. Int J Syst Bacteriol 1990;40:254-60.

51. Mijs W, de Haas P, Rossau R, Van der Laan T, Rigouts L, Portaels F, et al. Molecular evidence to support a proposal to reserve the designation Mycobacterium avium subsp. avium for bird-type isolates and 'M. avium subsp. hominissuis' for the human/porcine type of M. avium. Int J Syst Evol Microbiol 2002;52:1505-18.

52. Brooks RW, Parker BC, Gruft H, Falkinham JO 3rd. Epidemiology of infection by nontuberculous mycobacteria. V. Numbers in eastern United States soils and correlation with soil characteristics. Am Rev Respir Dis 1984;130:630-3.

53. Kirschner RA Jr, Parker BC, Falkinham JO 3rd. Epidemiology of infection by nontuberculous mycobacteria. Mycobacterium avium, Mycobacterium intracellulare, and Mycobacterium scrofulaceum in acid, brown-water swamps of the southeastern United States and their association with environmental variables. Am Rev Respir Dis 1992; 145:271-5.

54. Ichiyama S, Shimokata K, Tsukamura M. The isolation of Mycobacterium avium complex from soil, water, and dusts. Microbiol Immunol 1988;32:733-9.

55. Katila ML, livanainen E, Torkko P, Kauppinen J, Martikainen $\mathrm{P}$, Vaananen $\mathrm{P}$. Isolation of potentially pathogenic mycobacteria in the Finnish environment. Scand J Infect Dis Suppl 1995;98:9-11.

56. von Reyn CF, Waddell RD, Eaton T, Arbeit RD, Maslow JN, Barber TW, et al. Isolation of Mycobacterium avium complex from water in the United States, Finland, Zaire, and Kenya. J Clin Microbiol 1993;31:3227-30.

57. Nishiuchi Y, Maekura R, Kitada S, Tamaru A, Taguri T, Kira $\mathrm{Y}$, et al. The recovery of Mycobacterium avium-intracellulare complex (MAC) from the residential bathrooms of patients with pulmonary MAC. Clin Infect Dis 2007;45: 347-51.

58. Nishiuchi Y, Tamura A, Kitada S, Taguri T, Matsumoto S, Tateishi Y, et al. Mycobacterium avium complex organisms predominantly colonize in the bathtub inlets of patients' bathrooms. Jpn J Infect Dis 2009;62:182-6.

59. Tichenor WS, Thurlow J, McNulty S, Brown-Elliott BA, Wallace RJ Jr, Falkinham JO 3rd. Nontuberculous Mycobacteria in household plumbing as possible cause of chronic rhinosinusitis. Emerg Infect Dis 2012;18:1612-7.

60. lakhiaeva E, McNulty S, Brown Elliott BA, Falkinham JO 3rd, Williams MD, Vasireddy R, et al. Mycobacterial interspersed repetitive-unit-variable-number tandem-repeat (MIRU-VNTR) genotyping of mycobacterium intracellulare for strain comparison with establishment of a PCRbased database. J Clin Microbiol 2013;51:409-16.

61. Whiley H, Keegan A, Giglio S, Bentham R. Mycobacterium avium complex: the role of potable water in disease transmission. J Appl Microbiol 2012;113:223-32.

62. Tsukamura M, Kita N, Shimoide H, Arakawa H, Kuze A. Studies on the epidemiology of nontuberculous mycobacteriosis in Japan. Am Rev Respir Dis 1988;137:12804.

63. Park HK, Koh WJ, Shim TS, Kwon OJ. Clinical characteristics and treatment outcomes of Mycobacterium kansasii lung disease in Korea. Yonsei Med J 2010;51:552-6.

64. Moon SM, Park HY, Jeon K, Kim SY, Chung MJ, Huh HJ, et al. Clinical significance of Mycobacterium kansasii isolates from respiratory specimens. PLoS One 2015;10: e0139621.

65. Johnston JC, Chiang L, Elwood K. Mycobacterium kansasii. Microbiol Spectr 2017;5:1-9.

66. Steadham JE. High-catalase strains of Mycobacterium kansasii isolated from water in Texas. J Clin Microbiol 1980;11:496-8. 
67. Engel HW, Berwald LG, Havelaar AH. The occurrence of Mycobacterium kansasii in tapwater. Tubercle 1980;61: 21-6.

68. Picardeau M, Prod'Hom G, Raskine L, LePennec MP, Vincent V. Genotypic characterization of five subspecies of Mycobacterium kansasii. J Clin Microbiol 1997;35:25-32.

69. Zhang Y, Mann LB, Wilson RW, Brown-Elliott BA, Vincent $V$, linuma $Y$, et al. Molecular analysis of Mycobacterium kansasii isolates from the United States. J Clin Microbiol 2004;42:119-25.

70. Medjahed H, Gaillard JL, Reyrat JM. Mycobacterium abscessus: a new player in the mycobacterial field. Trends Microbiol 2010;18:117-23.

71. Nessar R, Cambau E, Reyrat JM, Murray A, Gicquel B. Mycobacterium abscessus: a new antibiotic nightmare. J Antimicrob Chemother 2012;67:810-8.

72. Koh WJ, Stout JE, Yew WW. Advances in the management of pulmonary disease due to Mycobacterium abscessus complex. Int J Tuberc Lung Dis 2014;18:1141-8.

73. Tortoli E, Kohl TA, Brown-Elliott BA, Trovato A, Leao SC, Garcia MJ, et al. Emended description of Mycobacterium abscessus, Mycobacterium abscessus subsp. abscessus and Mycobacteriumabscessus subsp. bolletii and designation of Mycobacteriumabscessus subsp. massiliense comb. nov. Int J Syst Evol Microbiol 2016; 66:4471-9.

74. Brown-Elliott BA, Wallace RJ Jr. Clinical and taxonomic status of pathogenic nonpigmented or late-pigmenting rapidly growing mycobacteria. Clin Microbiol Rev 2002; 15:716-46.

75. Benwill JL, Wallace RJ Jr. Mycobacterium abscessus: challenges in diagnosis and treatment. Curr Opin Infect Dis 2014;27:506-10.

76. Thomson RM, Carter R, Tolson C, Coulter C, Huygens F, Hargreaves M. Factors associated with the isolation of Nontuberculous mycobacteria (NTM) from a large municipal water system in Brisbane, Australia. BMC Microbiol 2013;13:89.

77. Kothavade RJ, Dhurat RS, Mishra SN, Kothavade UR. Clinical and laboratory aspects of the diagnosis and management of cutaneous and subcutaneous infections caused by rapidly growing mycobacteria. Eur J Clin Microbiol Infect Dis 2013;32:161-88.

78. Jeon K, Kwon OJ, Lee NY, Kim BJ, Kook YH, Lee SH, et al. Antibiotic treatment of Mycobacterium abscessus lung disease: a retrospective analysis of 65 patients. Am J Respir Crit Care Med 2009;180:896-902.
79. Koh WJ, Jeon K, Lee NY, Kim BJ, Kook YH, Lee SH, et al. Clinical significance of differentiation of Mycobacterium massiliense from Mycobacterium abscessus. Am J Respir Crit Care Med 2011;183:405-10.

80. Koh WJ, Jeong BH, Jeon K, Kim SY, Park KU, Park HY, et al. Oral macrolide therapy following short-term combination antibiotic treatment of Mycobacterium massiliense lung disease. Chest 2016;150:1211-21.

81. Koh WJ, Jeong BH, Kim SY, Jeon K, Park KU, Jhun BW, et al. Mycobacterial characteristics and treatment outcomes in Mycobacterium abscessus lung disease. Clin Infect Dis 2017;64:309-16.

82. Johnson MM, Odell JA. Nontuberculous mycobacterial pulmonary infections. J Thorac Dis 2014;6:210-20.

83. Houben EN, Korotkov KV, Bitter W. Take five: type VII secretion systems of mycobacteria. Biochim Biophys Acta 2014;1843:1707-16.

84. Devulder G, Perouse de Montclos M, Flandrois JP. A multigene approach to phylogenetic analysis using the genus Mycobacterium as a model. Int J Syst Evol Microbiol 2005;55:293-302.

85. Gey Van Pittius NC, Gamieldien J, Hide W, Brown GD, Siezen RJ, Beyers AD. The ESAT- 6 gene cluster of Mycobacterium tuberculosis and other high $\mathrm{G}+\mathrm{C}$ Gram-positive bacteria. Genome Biol 2001;2:RESEARCH0044.

86. Bitter W, Houben EN, Bottai D, Brodin P, Brown EJ, Cox JS, et al. Systematic genetic nomenclature for type VII secretion systems. PLoS Pathog 2009;5:e1000507.

87. Wee WY, Dutta A, Choo SW. Comparative genome analyses of mycobacteria give better insights into their evolution. PLoS One 2017;12:e0172831.

88. Koh WJ. Nontuberculous mycobacteria: overview. Microbiol Spectr 2017;5. https://doi.org/10.1128/microbiolspec.TNMI7-0024-2016.

89. Adjemian J, Olivier KN, Seitz AE, Holland SM, Prevots DR. Prevalence of nontuberculous mycobacterial lung disease in U.S. medicare beneficiaries. Am J Respir Crit Care Med 2012;185:881-6.

90. Henry MT, Inamdar L, O'Riordain D, Schweiger M, Watson JP. Nontuberculous mycobacteria in non-HIV patients: epidemiology, treatment and response. Eur Respir J 2004;23:741-6.

91. Marras TK, Mehta M, Chedore P, May K, Al Houqani M, Jamieson F. Nontuberculous mycobacterial lung infections in Ontario, Canada: clinical and microbiological characteristics. Lung 2010;188:289-99.

92. Andrejak C, Thomsen VO, Johansen IS, Riis A, Benfield 
TL, Duhaut P, et al. Nontuberculous pulmonary mycobacteriosis in Denmark: incidence and prognostic factors. Am J Respir Crit Care Med 2010;181:514-21.

93. Ojo O, Lagan AL, Rajendran V, Spanjer A, Chen L, Sohal SS, et al. Pathological changes in the COPD lung mesenchyme: novel lessons learned from in vitro and in vivo studies. Pulm Pharmacol Ther 2014;29:121-8.

94. Hoefsloot W, van Ingen J, Magis-Escurra C, Reijers MH, van Soolingen D, Dekhuijzen RP, et al. Prevalence of nontuberculous mycobacteria in COPD patients with exacerbations. J Infect 2013;66:542-5.

95. Yeh JJ, Wang YC, Sung FC, Chou CY, Kao CH. Nontuberculosis mycobacterium disease is a risk factor for chronic obstructive pulmonary disease: a nationwide cohort study. Lung 2014;192:403-11.

96. Olivier KN, Weber DJ, Wallace RJ Jr, Faiz AR, Lee JH, Zhang Y, et al. Nontuberculous mycobacteria. I: multicenter prevalence study in cystic fibrosis. Am J Respir Crit Care Med 2003;167:828-34.

97. Esther CR Jr, Esserman DA, Gilligan P, Kerr A, Noone PG. Chronic Mycobacterium abscessus infection and lung function decline in cystic fibrosis. J Cyst Fibros 2010;9: 117-23.

98. Sermet-Gaudelus I, Le Bourgeois M, Pierre-Audigier C, Offredo C, Guillemot D, Halley S, et al. Mycobacterium abscessus and children with cystic fibrosis. Emerg Infect Dis 2003;9:1587-91.

99. Roux AL, Catherinot E, Ripoll F, Soismier N, Macheras E, Ravilly S, et al. Multicenter study of prevalence of nontuberculous mycobacteria in patients with cystic fibrosis in France. J Clin Microbiol 2009;47:4124-8.

100. Mirsaeidi M, Hadid W, Ericsoussi B, Rodgers D, Sadikot RT. Non-tuberculous mycobacterial disease is common in patients with non-cystic fibrosis bronchiectasis. Int J Infect Dis 2013;17:e1000-4.

101. Griffith DE, Aksamit TR. Bronchiectasis and nontuberculous mycobacterial disease. Clin Chest Med 2012;33:283 $-95$.

102. Bonaiti G, Pesci A, Marruchella A, Lapadula G, Gori A, Aliberti S. Nontuberculous mycobacteria in noncystic fibrosis bronchiectasis. Biomed Res Int 2015;2015:197950.

103. Wickremasinghe M, Ozerovitch LJ, Davies G, Wodehouse T, Chadwick MV, Abdallah S, et al. Non-tuberculous mycobacteria in patients with bronchiectasis. Thorax 2005;60:1045-51.

104. Kunst H, Wickremasinghe M, Wells A, Wilson R. Nontuberculous mycobacterial disease and Aspergillus-relat- ed lung disease in bronchiectasis. Eur Respir J 2006; 28:352-7.

105. Matveychuk A, Fuks L, Priess R, Hahim I, Shitrit D. Clinical and radiological features of Mycobacterium kansasii and other NTM infections. Respir Med 2012;106:1472-7.

106. Yew WW, Chiang CY, Lumb R, Islam T. Are pulmonary non-tuberculous mycobacteria of concern in the Western Pacific Region? Int J Tuberc Lung Dis 2015;19:499500.

107. Hwang SM, Lim MS, Hong YJ, Kim TS, Park KU, Song J, et al. Simultaneous detection of Mycobacterium tuberculosis complex and nontuberculous mycobacteria in respiratory specimens. Tuberculosis (Edinb) 2013;93:6426.

108. Damaraju D, Jamieson F, Chedore P, Marras TK. Isolation of non-tuberculous mycobacteria among patients with pulmonary tuberculosis in Ontario, Canada. Int J Tuberc Lung Dis 2013;17:676-81.

109. Jun HJ, Jeon K, Um SW, Kwon OJ, Lee NY, Koh WJ. Nontuberculous mycobacteria isolated during the treatment of pulmonary tuberculosis. Respir Med 2009;103: 1936-40.

110. Chu H, Zhao L, Xiao H, Zhang Z, Zhang J, Gui T, et al. Prevalence of nontuberculous mycobacteria in patients with bronchiectasis: a meta-analysis. Arch Med Sci 2014;10:661-8.

111. Noone PG, Leigh MW, Sannuti A, Minnix SL, Carson JL, Hazucha M, et al. Primary ciliary dyskinesia: diagnostic and phenotypic features. Am J Respir Crit Care Med 2004; 169:459-67.

112. Horani A, Ferkol TW, Shoseyov D, Wasserman MG, Oren YS, Kerem B, et al. LRRC6 mutation causes primary ciliary dyskinesia with dynein arm defects. PLoS One 2013; 8:e59436.

113. Prince DS, Peterson DD, Steiner RM, Gottlieb JE, Scott R, Israel HL, et al. Infection with Mycobacterium avium complex in patients without predisposing conditions. $\mathrm{N}$ Engl J Med 1989;321:863-8.

114. Kim RD, Greenberg DE, Ehrmantraut ME, Guide SV, Ding $L$, Shea $Y$, et al. Pulmonary nontuberculous mycobacterial disease: prospective study of a distinct preexisting syndrome. Am J Respir Crit Care Med 2008;178:1066-74.

115. Kartalija M, Ovrutsky AR, Bryan CL, Pott GB, Fantuzzi G, Thomas J, et al. Patients with nontuberculous mycobacterial lung disease exhibit unique body and immune phenotypes. Am J Respir Crit Care Med 2013;187:197205. 
116. Ziedalski TM, Kao PN, Henig NR, Jacobs SS, Ruoss SJ. Prospective analysis of cystic fibrosis transmembrane regulator mutations in adults with bronchiectasis or pulmonary nontuberculous mycobacterial infection. Chest 2006;130:995-1002.

117. Colombo RE, Hill SC, Claypool RJ, Holland SM, Olivier $\mathrm{KN}$. Familial clustering of pulmonary nontuberculous mycobacterial disease. Chest 2010;137:629-34.

118. Fowler CJ, Olivier KN, Leung JM, Smith CC, Huth AG, Root $\mathrm{H}$, et al. Abnormal nasal nitric oxide production, ciliary beat frequency, and Toll-like receptor response in pulmonary nontuberculous mycobacterial disease epithelium. Am J Respir Crit Care Med 2013;187:1374-81.

119. Hwang JH, Koh WJ, Kim EJ, Kang EH, Suh GY, Chung MP, et al. Partial interferon-gamma receptor deficiency and non-tuberculous mycobacterial lung disease. Tuberculosis (Edinb) 2006;86:382-5.

120. Szymanski EP, Leung JM, Fowler CJ, Haney C, Hsu AP, Chen $F$, et al. Pulmonary nontuberculous mycobacterial infection. A multisystem, multigenic disease. Am J Respir Crit Care Med 2015;192:618-28.

121. Wu UI, Holland SM. Host susceptibility to non-tuberculous mycobacterial infections. Lancet Infect Dis 2015;15: 968-80.

122. Casanova JL, Holland SM, Notarangelo LD. Inborn errors of human JAKs and STATs. Immunity 2012;36:515-28.

123. Rosenzweig SD, Holland SM. Defects in the interferon-gamma and interleukin-12 pathways. Immunol Rev 2005;203:38-47.

124. Gomes MS, Florido M, Cordeiro JV, Teixeira CM, Takeuchi 0 , Akira S, et al. Limited role of the Toll-like receptor-2 in resistance to Mycobacterium avium. Immunology 2004; 111:179-85.

125. Sampaio EP, Elloumi HZ, Zelazny A, Ding L, Paulson ML, Sher A, et al. Mycobacterium abscessus and M. avium trigger Toll-like receptor 2 and distinct cytokine response in human cells. Am J Respir Cell Mol Biol 2008; 39:431-9.

126. Briken V, Ahlbrand SE, Shah S. Mycobacterium tuberculosis and the host cell inflammasome: a complex relationship. Front Cell Infect Microbiol 2013;3:62.

127. Bermudez LE, Wu M, Young LS. Interleukin-12-stimulated natural killer cells can activate human macrophages to inhibit growth of Mycobacterium avium. Infect Immun 1995;63:4099-104.

128. Appelberg R, Castro AG, Pedrosa J, Minoprio P. Role of interleukin- 6 in the induction of protective T cells during mycobacterial infections in mice. Immunology 1994;82: 361-4.

129. Swart RM, van Ingen J, van Soolingen $D$, Slingerland R, Hendriks WD, den Hollander JG. Nontuberculous mycobacteria infection and tumor necrosis factor-alpha antagonists. Emerg Infect Dis 2009;15:1700-1.

130. Winthrop KL, Chang E, Yamashita S, lademarco MF, LoBue PA. Nontuberculous mycobacteria infections and anti-tumor necrosis factor-alpha therapy. Emerg Infect Dis 2009;15:1556-61.

131. Casanova JL, Abel L. Genetic dissection of immunity to mycobacteria: the human model. Annu Rev Immunol 2002;20:581-620.

132. Skamene E. Genetic control of susceptibility to infections with intracellular pathogens. Pathol Biol (Paris) 1998;46:689-92.

133. Bogunovic D, Byun M, Durfee LA, Abhyankar A, Sanal O, Mansouri $D$, et al. Mycobacterial disease and impaired IFN- $\gamma$ immunity in humans with inherited ISG15 deficiency. Science 2012;337:1684-8.

134. Hambleton S, Salem S, Bustamante J, Bigley V, Boisson-Dupuis $\mathrm{S}$, Azevedo J, et al. IRF8 mutations and human dendritic-cell immunodeficiency. N Engl J Med 2011;365:127-38.

135. Browne SK, Burbelo PD, Chetchotisakd P, Suputtamongkol Y, Kiertiburanakul S, Shaw PA, et al. Adult-onset immunodeficiency in Thailand and Taiwan. N Engl J Med 2012;367:725-34.

136. Valour F, Perpoint T, Senechal A, Kong XF, Bustamante J, Ferry T, et al. Interferon- $\gamma$ autoantibodies as predisposing factor for nontuberculous mycobacterial infection. Emerg Infect Dis 2016;22:1124-6.

137. Cole ST, Brosch R, Parkhill J, Garnier T, Churcher C, Harris $\mathrm{D}$, et al. Deciphering the biology of Mycobacterium tuberculosis from the complete genome sequence. $\mathrm{Na}$ ture 1998;393:537-44.

138. Brown-Elliott BA, Nash KA, Wallace RJ Jr. Antimicrobial susceptibility testing, drug resistance mechanisms, and therapy of infections with nontuberculous mycobacteria. Clin Microbiol Rev 2012;25:545-82.

139. Daffe M, Draper P. The envelope layers of mycobacteria with reference to their pathogenicity. Adv Microb Physiol 1998;39:131-203.

140. Nash KA. Intrinsic macrolide resistance in Mycobacterium smegmatis is conferred by a novel erm gene, erm(38). Antimicrob Agents Chemother 2003;47:3053-60.

141. Nash KA, Brown-Elliott BA, Wallace RJ Jr. A novel gene, 
erm(41), confers inducible macrolide resistance to clinical isolates of Mycobacterium abscessus but is absent from Mycobacterium chelonae. Antimicrob Agents Chemother 2009;53:1367-76.

142. Nash KA, Zhang Y, Brown-Elliott BA, Wallace RJ Jr. Molecular basis of intrinsic macrolide resistance in clinical isolates of Mycobacterium fortuitum. J Antimicrob Chemother 2005;55:170-7.

143. Kim HY, Kim BJ, Kook Y, Yun YJ, Shin JH, Kim BJ, et al. Mycobacterium massiliense is differentiated from Mycobacterium abscessus and Mycobacterium bolletii by erythromycin ribosome methyltransferase gene (erm) and clarithromycin susceptibility patterns. Microbiol Immunol 2010;54:347-53.

144. Alcaide F, Pfyffer GE, Telenti A. Role of embB in natural and acquired resistance to ethambutol in mycobacteria. Antimicrob Agents Chemother 1997;41:2270-3.

145. Sreevatsan S, Stockbauer KE, Pan X, Kreiswirth BN, Moghazeh SL, Jacobs WR Jr, et al. Ethambutol resistance in Mycobacterium tuberculosis: critical role of embB mutations. Antimicrob Agents Chemother 1997; 41:1677-81.

146. Matrat S, Aubry A, Mayer C, Jarlier V, Cambau E. Mutagenesis in the alpha3alpha4 GyrA helix and in the Toprim domain of GyrB refines the contribution of Mycobacterium tuberculosis DNA gyrase to intrinsic resistance to quinolones. Antimicrob Agents Chemother 2008;52:2909-14.

147. Guillemin I, Jarlier V, Cambau E. Correlation between quinolone susceptibility patterns and sequences in the $A$ and $B$ subunits of DNA gyrase in mycobacteria. Antimicrob Agents Chemother 1998;42:2084-8.

148. Burian J, Ramon-Garcia S, Sweet G, Gomez-Velasco A, Av-Gay Y, Thompson CJ. The mycobacterial transcriptional regulator whiB7 gene links redox homeostasis and intrinsic antibiotic resistance. J Biol Chem 2012; 287:299-310.

149. Morris RP, Nguyen L, Gatfield J, Visconti K, Nguyen K, Schnappinger $D$, et al. Ancestral antibiotic resistance in Mycobacterium tuberculosis. Proc Natl Acad Sci U S A 2005;102:12200-5.

150. Poole K. Efflux pumps as antimicrobial resistance mechanisms. Ann Med 2007;39:162-76.

151. Piddock LJ. Multidrug-resistance efflux pumps: not just for resistance. Nat Rev Microbiol 2006;4:629-36.

152. De Rossi E, Ainsa JA, Riccardi G. Role of mycobacterial efflux transporters in drug resistance: an unresolved question. FEMS Microbiol Rev 2006;30:36-52.
153. Louw GE, Warren RM, Gey van Pittius NC, McEvoy CR, Van Helden PD, Victor TC. A balancing act: efflux/influx in mycobacterial drug resistance. Antimicrob Agents Chemother 2009;53:3181-9.

154. Rodrigues L, Sampaio D, Couto I, Machado D, Kern WV, Amaral $L$, et al. The role of efflux pumps in macrolide resistance in Mycobacterium avium complex. Int J Antimicrob Agents 2009;34:529-33.

155. Deshayes C, Bach H, Euphrasie D, Attarian R, Coureuil M, Sougakoff W, et al. MmpS4 promotes glycopeptidolipids biosynthesis and export in Mycobacterium smegmatis. Mol Microbiol 2010;78:989-1003.

156. Domenech P, Reed MB, Barry CE 3rd. Contribution of the Mycobacterium tuberculosis MmpL protein family to virulence and drug resistance. Infect Immun 2005;73: 3492-501.

157. Tseng TT, Gratwick KS, Kollman J, Park D, Nies DH, Goffeau A, et al. The RND permease superfamily: an ancient, ubiquitous and diverse family that includes human disease and development proteins. J Mol Microbiol Biotechnol 1999;1:107-25.

158. Pasca MR, Guglierame P, De Rossi E, Zara F, Riccardi G. MmpL7 gene of Mycobacterium tuberculosis is responsible for isoniazid efflux in Mycobacterium smegmatis. Antimicrob Agents Chemother 2005;49:4775-7.

159. Halloum I, Viljoen A, Khanna V, Craig D, Bouchier C, Brosch $\mathrm{R}$, et al. Resistance to thiacetazone derivatives active against Mycobacterium abscessus involves mutations in the MmpL5 transcriptional repressor MAB_4384. Antimicrob Agents Chemother 2017;61:e02509-16.

160. Alexander DC, Vasireddy R, Vasireddy S, Philley JV, Brown-Elliott BA, Perry BJ, et al. Emergence of mmpT5 variants during bedaquiline treatment of Mycobacterium intracellulare lung disease. J Clin Microbiol 2017;55: 574-84.

161. Blair JM, Webber MA, Baylay AJ, Ogbolu DO, Piddock LJ. Molecular mechanisms of antibiotic resistance. Nat Rev Microbiol 2015;13:42-51.

162. van Hoek AH, Mevius D, Guerra B, Mullany P, Roberts AP, Aarts HJ. Acquired antibiotic resistance genes: an overview. Front Microbiol 2011;2:203.

163. Klein JL, Brown TJ, French GL. Rifampin resistance in Mycobacterium kansasii is associated with rpoB mutations. Antimicrob Agents Chemother 2001;45:3056-8.

164. Obata S, Zwolska Z, Toyota E, Kudo K, Nakamura A, Sawai T, et al. Association of rpoB mutations with rifampicin resistance in Mycobacterium avium. Int J Antimi- 
crob Agents 2006;27:32-9.

165. Meier A, Heifets L, Wallace RJ Jr, Zhang Y, Brown BA, Sander $\mathrm{P}$, et al. Molecular mechanisms of clarithromycin resistance in Mycobacterium avium: observation of multiple 23S rDNA mutations in a clonal population. J Infect Dis 1996;174:354-60.

166. Wallace RJ Jr, Meier A, Brown BA, Zhang Y, Sander P, Onyi GO, et al. Genetic basis for clarithromycin resistance among isolates of Mycobacterium chelonae and Mycobacterium abscessus. Antimicrob Agents Chemother 1996;40:1676-81.

167. Burman WJ, Stone BL, Brown BA, Wallace RJ Jr, Bottger EC. AIDS-related Mycobacterium kansasii infection with initial resistance to clarithromycin. Diagn Microbiol Infect Dis 1998;31:369-71.

168. Bastian S, Veziris N, Roux AL, Brossier F, Gaillard JL, Jarlier V, et al. Assessment of clarithromycin susceptibility in strains belonging to the Mycobacterium abscessus group by erm(41) and rrl sequencing. Antimicrob Agents Chemother 2011;55:775-81.

169. Choi H, Kim SY, Lee H, Jhun BW, Park HY, Jeon K, et al. Clinical characteristics and treatment outcomes of patients with macrolide-resistant Mycobacterium massiliense lung disease. Antimicrob Agents Chemother 2017; 61:e02189-16.

170. Mougari F, Bouziane F, Crockett F, Nessar R, Chau F, Veziris $\mathrm{N}$, et al. Selection of resistance to clarithromycin in Mycobacterium abscessus subspecies. Antimicrob Agents Chemother 2016;61:e00943-16.

171. Sander P, Bottger EC. Mycobacteria: genetics of resistance and implications for treatment. Chemotherapy
1999;45:95-108.

172. Prammananan T, Sander P, Brown BA, Frischkorn K, Onyi GO, Zhang Y, et al. A single 16 S ribosomal RNA substitution is responsible for resistance to amikacin and other 2-deoxystreptamine aminoglycosides in Mycobacterium abscessus and Mycobacterium chelonae. J Infect Dis 1998;177:1573-81.

173. Wallace RJ Jr, Hull SI, Bobey DG, Price KE, Swenson JM, Steele LC, et al. Mutational resistance as the mechanism of acquired drug resistance to aminoglycosides and antibacterial agents in Mycobacterium fortuitum and Mycobacterium chelonei. Evidence is based on plasmid analysis, mutational frequencies, and aminoglycoside-modifying enzyme assays. Am Rev Respir Dis 1985; 132:409-16.

174. Nessar R, Reyrat JM, Murray A, Gicquel B. Genetic analysis of new $16 \mathrm{~S}$ rRNA mutations conferring aminoglycoside resistance in Mycobacterium abscessus. J Antimicrob Chemother 2011;66:1719-24.

175. Maus CE, Plikaytis BB, Shinnick TM. Molecular analysis of cross-resistance to capreomycin, kanamycin, amikacin, and viomycin in Mycobacterium tuberculosis. Antimicrob Agents Chemother 2005;49:3192-7.

176. Taniguchi H, Chang B, Abe C, Nikaido Y, Mizuguchi Y, Yoshida SI. Molecular analysis of kanamycin and viomycin resistance in Mycobacterium smegmatis by use of the conjugation system. J Bacteriol 1997;179:4795-801.

177. Suzuki Y, Katsukawa C, Tamaru A, Abe C, Makino M, Mizuguchi Y, et al. Detection of kanamycin-resistant Mycobacterium tuberculosis by identifying mutations in the 16S rRNA gene. J Clin Microbiol 1998;36:1220-5. 